\title{
Fate of the UPR marker protein Kar2/Bip and autophagic processes in fed-batch cultures of secretory insulin precursor producing Pichia pastoris
}

\author{
Gustavo Roth ${ }^{1}$, Ana Letícia Vanz ${ }^{1}$, Heinrich Lünsdorf ${ }^{2}$, Manfred Nimtz ${ }^{2}$ and Ursula Rinas ${ }^{1,2^{*}}$
}

\begin{abstract}
Background: Secretory recombinant protein production with Pichia (syn. Komagataella) pastoris is commonly associated with the induction of an unfolded protein response (UPR) usually apparent through increased intracellular levels of endoplasmic reticulum (ER) resident chaperones such as Kar2/Bip. During methanol-induced secretory production of an insulin precursor (IP) under industrially relevant fed-batch conditions the initially high level of intracellular Kar2/ Bip after batch growth on glycerol unexpectedly declined in the following methanol fed-batch phase misleadingly suggesting that IP production had a low impact on UPR activation.

Results: Analysis of the protein production independent level of Kar2/Bip revealed that high Kar2/Bip levels were reached in the exponential growth phase of glycerol batch cultures followed by a strong decline of Kar2/Bip during entry into stationary phase. Ultra-structural cell morphology studies revealed autophagic processes (e.g. ER phagy) at the end of the glycerol batch phase most likely responsible for the degradation of ER resident chaperones such as Kar2/Bip. The pre-induction level of Kar2/Bip did not affect the IP secretion efficiency in the subsequent methanolinduced IP production phase. During growth on methanol intracellular Kar2/Bip levels declined in IP producing and non-producing host cells. However, extracellular accumulation of Kar2/Bip was observed in IP-producing cultures but not in non-producing controls. Most importantly, the majority of the extracellular Kar2/Bip accumulated in the culture supernatant of IP producing cells as truncated protein (approx. $35 \mathrm{kDa}$ ).
\end{abstract}

Conclusions: Rapid growth leads to higher basal levels of the major UPR marker protein Kar2/Bip independent of recombinant protein production. Entry into stationary phase or slower growth on poorer substrate, e.g. methanol, leads to a lower basal Kar2/Bip level. Methanol-induced secretory IP production elicits a strong UPR activation which counteracts the reduced UPR during slow growth on methanol. The major ER chaperone Kar2/Bip is found together with recombinant IP in the culture medium where full-length Kar2/Bip accumulates in addition to large amounts of truncated Kar2/Bip. Thus, for judging UPR activating properties of the produced protein it is important to additionally analyze the medium not only for intact Kar2/Bip but also for truncated versions of this UPR reporter protein.

Keywords: Autophagy, Kar2/Bip, Pichia pastoris, Unfolded protein response

\footnotetext{
*Correspondence: ursula.rinas@helmholtz-hzi.de

${ }^{2}$ Helmholtz Centre for Infection Research, Inhoffenstrasse 7,

38124 Brunswick, Germany

Full list of author information is available at the end of the article
} 


\section{Background}

The methylotrophic yeast Pichia (syn. Komagatella) pastoris is a well-established eukaryotic host for the production of heterologous proteins preferentially secreted into the medium to simplify further down-stream procedures [1-3].

Heterologous secretory protein production in $P$. pastoris is often connected to the induction of an unfolded protein response (UPR) leading to increased expression of UPR responsive genes [4-11] and correspondingly elevated intracellular levels of the encoded UPR responsive proteins encompassing endoplasmic reticulum (ER) resident chaperones and foldases [9, 12-14]. The most prominent ER chaperone, Kar2/Bip acts as the sensor protein for the presence of misfolded proteins but is also involved in chaperoning protein folding or targeting recalcitrant proteins to the endoplasmic reticulum associated degradation (ERAD) pathway thereby reducing protein misfolding associated stress in the ER [15]. Co-overproduction of Kar2/Bip in P. pastoris has been investigated for enhanced secretion of target proteins with mixed success $[11,16,17]$.

The impact of secretory recombinant protein production on UPR activation in P. pastoris through proteome analysis can be assessed by analysing the intracellular content of UPR responsive proteins such as Kar2/Bip [9, 12-14, 18]. In most cases, Kar2/Bip increases after induction of recombinant protein production as has been shown for the methanol-induced production of the intracellular ER-retained Hepatitis B surface antigen [13] but also during secretory production of trypsinogen [12] and an anti-CD3 immunotoxin [14]. Interestingly, Kar2/Bip was not identified among many other UPR responsive proteins in $P$. pastoris during secretory xylanase production using the sensitive iTRAQ LC-MS/MS analysis [9].

Surprisingly, a decrease of Kar2/Bip and other UPR related proteins was detected during methanol-induced secretory insulin precursor (IP) production in P. pastoris in shake flask but also in industrially relevant fed-batch cultures [18]. Compared to the non-producing host strain the decrease of the intracellular level of Kar2/Bip was less pronounced suggesting that production of IP elicits a detectable but not very strong UPR response which is repressed by a general culture condition dependent UPR down-regulation after the shift from batch growth on glycerol to fed-batch growth on methanol. It was hypothesized that unexpected high levels of intracellular Kar2/ Bip at the end of the glycerol batch phase may result from high initial glycerol concentrations, and a correspondingly high medium osmolarity, leading to an efficient secretion of IP during the following methanol-induced IP production phase.
The aim of this study was to analyze more deeply the impact of culture conditions on the basal level of Kar2/ Bip and the impact of the preinduction Kar2/Bip level on secretory IP production efficiency. The IP production related UPR analysis also encompassed the analysis of the culture medium for full-length and truncated versions of the UPR marker protein Kar2/Bip. Finally, the UPR analysis was complemented by electron microscopic cell studies to search for autophagic processes.

\section{Results \\ Influence of initial glycerol concentration and growth phase/rate on the protein production independent basal level of Kar2/Bip in batch culture}

The extent of the constitutive or basal level of the UPR in the absence of recombinant protein production was determined through analysis of the intracellular level of Kar2/Bip in cells growing on defined medium in controlled bioreactor batch cultures with glycerol as sole carbon source. The initial concentration of glycerol was varied from 30 to $125 \mathrm{~g} / \mathrm{L}$ and the level of intracellular Kar2/Bip followed during the time course of batch growth.

Surprisingly, these analyses revealed that intracellular Kar2/Bip levels were independent of the initial glycerol concentrations but highly dependent on the growth phase. Kar2/Bip level were highest during the exponential growth phase but declined rapidly to almost undetectable levels after cells entered into stationary phase suggesting active degradation of Kar2/Bip (Fig. 1). Similar profiles and intracellular Kar2 levels during batch growth were observed at initial glycerol concentrations ranging from 30 to $125 \mathrm{~g} / \mathrm{L}$ (Table 1, Additional file 1).

\section{Autophagic processes in P. pastoris entering stationary phase during growth on glycerol}

The sudden and strong decline of Kar2/Bip at the end of the glycerol batch phase indicated active degradation presumably caused by autophagic processes during entry into stationary phase. Autophagic processes are known to occur in glycerol grown $P$. pastoris during entry into stationary phase where around $20 \%$ of cells were observed to have vacuoles with embedded autophagic bodies [13]. An electron microscopic survey of IP producing cells at the end of the glycerol batch phase prior to methanolinduced IP production also revealed autophagic cells amongst others also cells at the beginning of ER- and ribophagy (Fig. 2). Autophagic processes involving ERand ribophagy at the end of the glycerol batch are not unique to the IP producing strain but were also observed at the end of the glycerol batch phase of a GS115 derived HBsAg production strain (data not shown, [13]). 


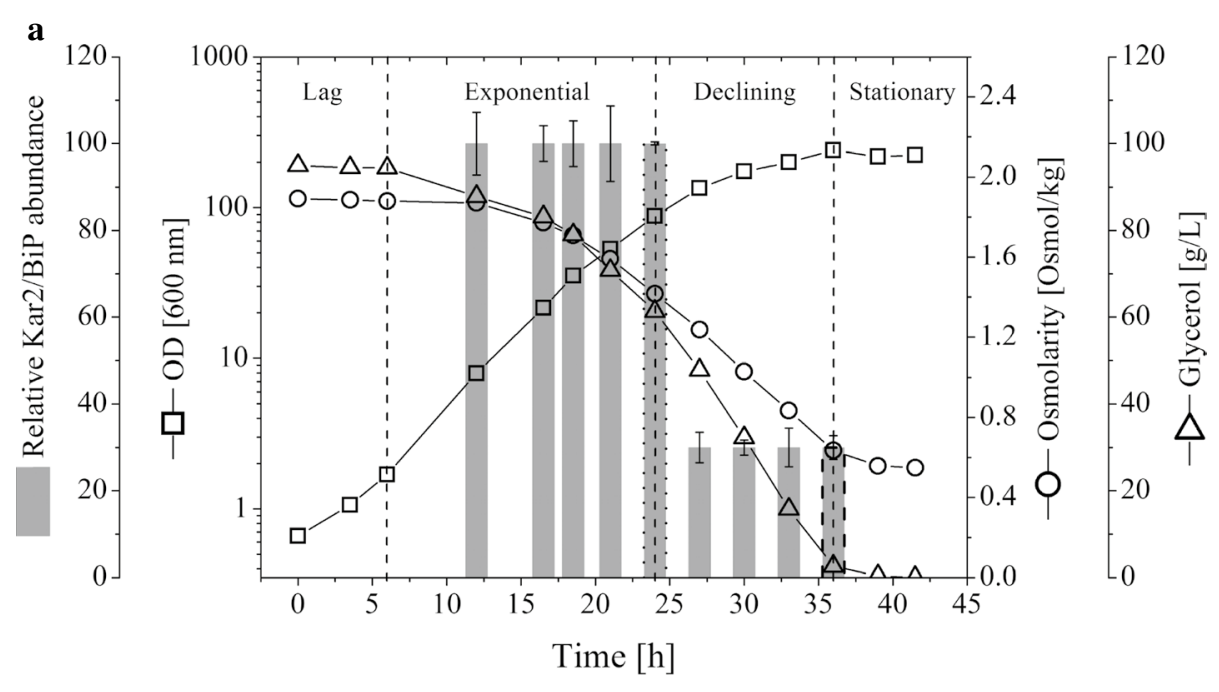

b $\mathrm{kDa}$

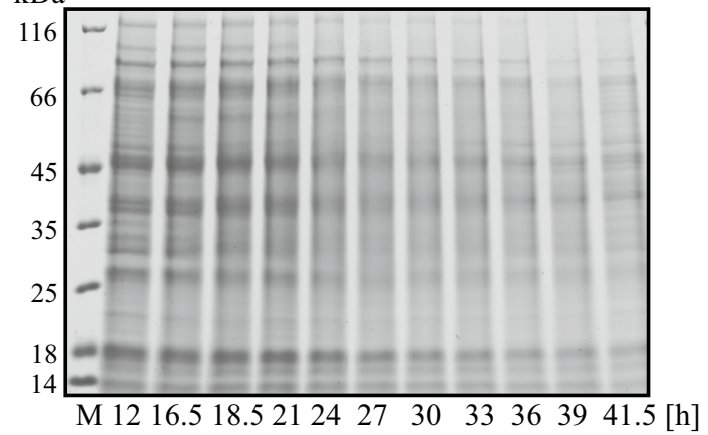

c $\mathrm{kDa}$

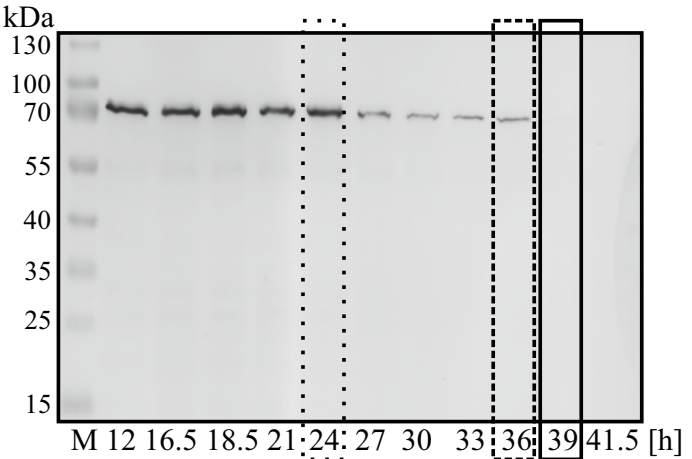

Fig. 1 Intracellular Kar2/Bip level during glycerol batch growth of P. pastoris X-33 carrying the aox 1 promoter-controlled IP gene. Cells were grown in the $2 \mathrm{~L}$ bioreactor in a batch procedure with $95 \mathrm{~g} / \mathrm{L}$ glycerol as carbon source. a The time-dependent relative intracellular Kar2/Bip abundance (gray bars), biomass (optical density: squares), glycerol concentration (triangles), and osmolarity (circles) of the culture broth are given. The dashed vertical lines point to the borders of indicated growth phases. b SDS-PAGE gels and c corresponding immunoblots probing for Kar2/Bip in total cell lysates. $\mathrm{M}$ denotes the molecular weight marker and the numbers on bottom of the lanes the post-inoculation sampling time points. Boxed lanes correspond to boxed bars in (a)

Table 1 Growth performance and intracellular Kar2/ Bip level of $P$. pastoris X-33 carrying the aox 1 promotercontrolled IP gene during batch growth in a $\mathbf{2} \mathbf{L}$ bioreactor with different initial glycerol concentrations

\begin{tabular}{lllll}
\hline Glycerol $(\mathrm{g} / \mathrm{L})$ & 30 & 60 & 95 & 125 \\
$\mu_{\max }(1 / \mathrm{h})$ & 0.26 & 0.19 & 0.18 & 0.18 \\
Osmolarity (Osmol/kg) & 0.8 & 1.4 & 1.9 & 2.5 \\
Relative Kar2/Bip abundance & 114 & 123 & 100 & 116 \\
\hline
\end{tabular}

Effect of pre-induction Kar2/Bip level on methanol induced secretory IP production kinetics and final IP concentrations To test if the growth phase, or more specifically, the Kar2/Bip level at the initiation of methanol-induced IP production, correlates positively with the efficiency of IP secretion, induction of IP synthesis was carried out through transfer of cells from different growth phases of the glycerol bioreactor batch culture into shake flask cultures containing complex methanol induction medium. IP production was carried out under conditions of pulsed methanol feeding.

These experiments clearly revealed that the kinetics of IP secretion as well as the final concentrations of extracellular IP were independent of the pre-induction growth phase, or more specifically, they were independent on the Kar2/Bip level at the onset of methanol induced IP production (Fig. 3a). These experiments also clearly proved that a high Kar2/Bip level at the onset of methanol-induced IP production did not correlate with more efficient IP secretion (Fig. 3a). On the contrary, final IP concentrations were even slightly higher (Fig. 3a) when induction was carried out using late 

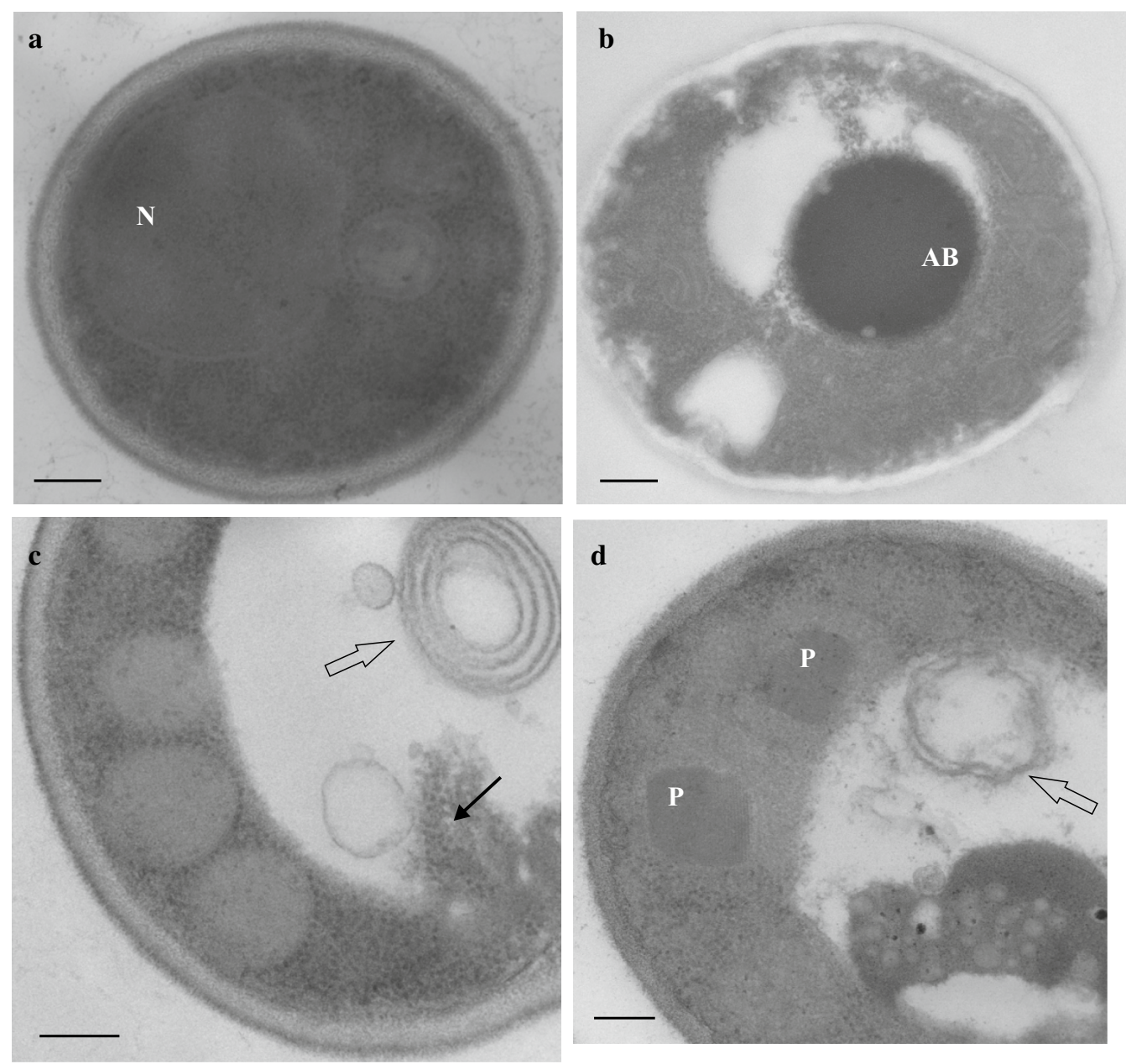

Fig. 2 Autophagic processes in P. pastoris approaching stationary phase in glycerol batch cultures and during methanol-induced IP production in fed-batch cultures. a-c Cells were first grown in a $15 \mathrm{~L}$ bioreactor in batch mode with $95 \mathrm{~g} / \mathrm{L}$ glycerol as carbon source as described previously [19]. Directly after depletion of glycerol and prior to methanol feeding cells were examined by transmission electron microscopy. Representative images of cells from the morphologically diverse population are shown. $\mathbf{d}$ After depletion of glycerol IP production was induced by methanol feeding as described before [19]. Representative image taken $48 \mathrm{~h}$ after the onset of methanol feeding. N: nucleus, AB: autophagic body, P: peroxisome, open arrows: membranous structures with the typical features of the delimiting ER membranes (ER-phagy), black arrow: ribosomes (ribophagy). For typical features of ER-phagy in electron micrographs of S. cerevisiae [32-34] and P. pastoris [29] please consult figures in indicated references. Bars represent $200 \mathrm{~nm}$

stationary phase cells which contained only negligible amounts of Kar2/Bip as determined by Western blot analysis and subsequent immunostaining (Fig. 3b, c).

\section{Secretory IP production results in extracellular accumulation of the UPR marker protein Kar2/Bip}

For studies on the post-induction UPR, the timecourse of intracellular Kar2/Bip levels were determined after the start of the methanol-induced IP production phase. In all experimental setups, intracellular Kar2/Bip reached or kept a low, almost undetectable level after transfer to methanol containing induction medium (Fig. 3b, c). Interestingly, in all IP producing cultures also extracellular accumulation of Kar2/Bip was observed (Fig. 3b, c). Control experiments with the host strain using identical culture conditions did not lead to the extracellular accumulation of Kar2/Bip clearly proving that Kar2/Bip secretion was connected to secretory IP production (Fig. 3c). Moreover, no extracellular Kar2/Bip was detected during the glycerol batch phase neither in the host nor in the production strain corroborating the correlation of extracellular Kar2/Bip accumulation to IP secretion (Fig. 3c). A quantitative analysis of Kar2/Bip additionally revealed that the extracellular Kar2/Bip resulted from de novo synthesis during the methanol phase and not from 

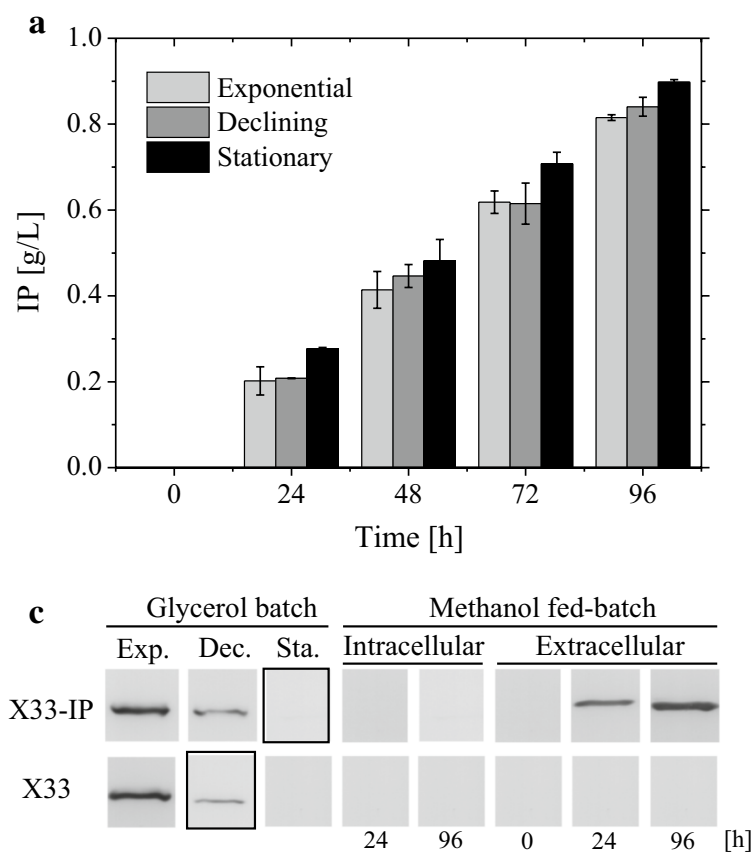

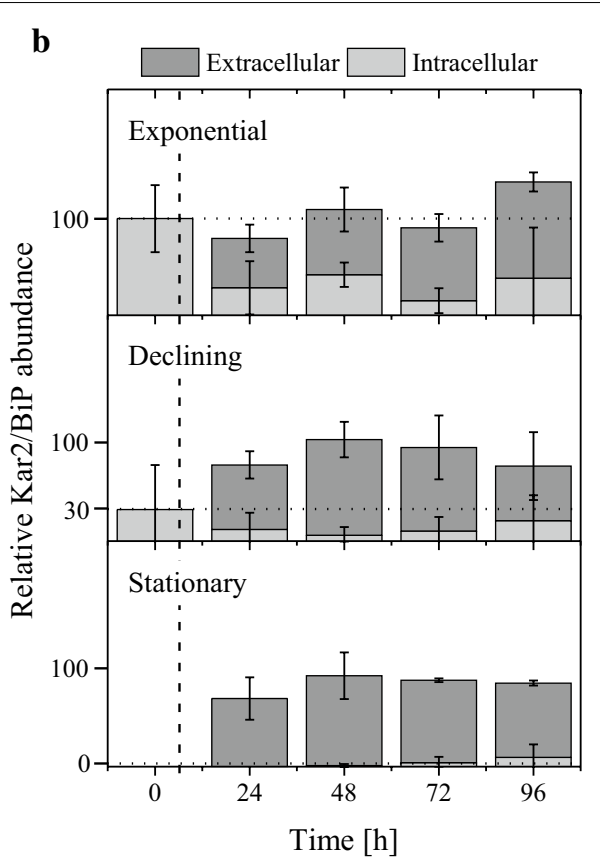

Fig. 3 Effect of pre-induction Kar2/Bip content on methanol induced IP production and post-induction Kar2/Bip level. Cells were first grown in the $10 \mathrm{~L}$ bioreactor in a batch procedure with $95 \mathrm{~g} / \mathrm{L}$ glycerol as carbon source. Subsequently, they were subjected to methanol-induced IP production in shake flask fed-batch cultures starting either with cells from the exponential, declining, or stationary growth phase of the batch culture. a Methanol-induced secretory IP production and $\mathbf{b}$ relative intra- and extracellular pre- and post-induction Kar2/Bip abundance. $\mathbf{c}$ Comparative immunoblots probing for intra- and extracellular Kar2/Bip from samples of IP producing and host cells taken from bioreactor glycerol batch and shake flask methanol fed-batch cultures. The bands inside the highlighted rectangles indicate the intracellular Kar2/Bip level prior to methanol addition

Kar2/Bip already formed before in the glycerol batch phase (Fig. 3b).

\section{The fate of Kar2/Bip in controlled bioreactor fed-batch cultures}

Detection of Kar2/Bip in the medium of IP-producing cells in shake flask cultures under conditions of pulsed methanol feeding prompted us to re-analyze UPR induction during IP production in industrially relevant controlled fed-batch cultures by focussing on the analysis for Kar2/Bip in cell free medium samples. Cells were initially grown on $95 \mathrm{~g} / \mathrm{L}$ glycerol, after depletion of glycerol secretory IP production was initiated by methanol addition to a final concentration of $2 \mathrm{~g} / \mathrm{L}$ which was kept constant by continuous methanol feeding (Fig. 4a, [19]).

Analysis of the intracellular Kar2/Bip level during the methanol-induced IP production phase revealed the expected time-dependent decrease of Kar2/Bip as reported previously (Fig. 4b, [18]). In addition, extracellular accumulation of Kar2/Bip was observed in the culture broth detectable by Western blot analysis with subsequent immunostaining (Fig. 4b). Moreover, Kar2/Bip was also detectable as a faint band in Coomassie stained gels (Fig. 4c). The identity of the faint band at approx. $70 \mathrm{kDa}$ in Coomassie stained gels as Kar2/Bip was verified by Maldi-ToF analysis (data not shown). Interestingly, Coomassie stained gels of cell free culture samples from IP producing cells of controlled fed-batch cultures also revealed a strong single broad band corresponding to protein(s) of a molecular mass of approx. $35 \mathrm{kDa}$ which were not reacting with antibodies against the ER retention signal HDEL (Fig. 4a, see also Fig. 3 in [19]). As the culture medium of $P$. pastoris usually does not contain endogenous Pichia proteins efforts were undertaken to identify these protein(s). Attempts by Maldi-ToF analysis were repeatedly unsuccessful.

Finally, the protein band of approx. $35 \mathrm{kDa}$ was subjected to HPLC-MS/MS analysis after in-gel tryptic digestion and mass spectrometric sequencing of the resulting peptides. These analyses revealed the presence of truncated Kar2/Bip as dominant component of this protein band (for details see also Additional file 2). Fulllength mature Kar2/Bip has a molecular mass of approx. $74 \mathrm{kDa}$, thus the truncated Kar2/Bip is only half of its original size. Since all Kar2/Bip peptides from the N-terminal part of the protein were of higher intensity than peptides originating from the C-terminal part of the protein, it can be concluded that the $\mathrm{C}$-terminal part of Kar2/ 

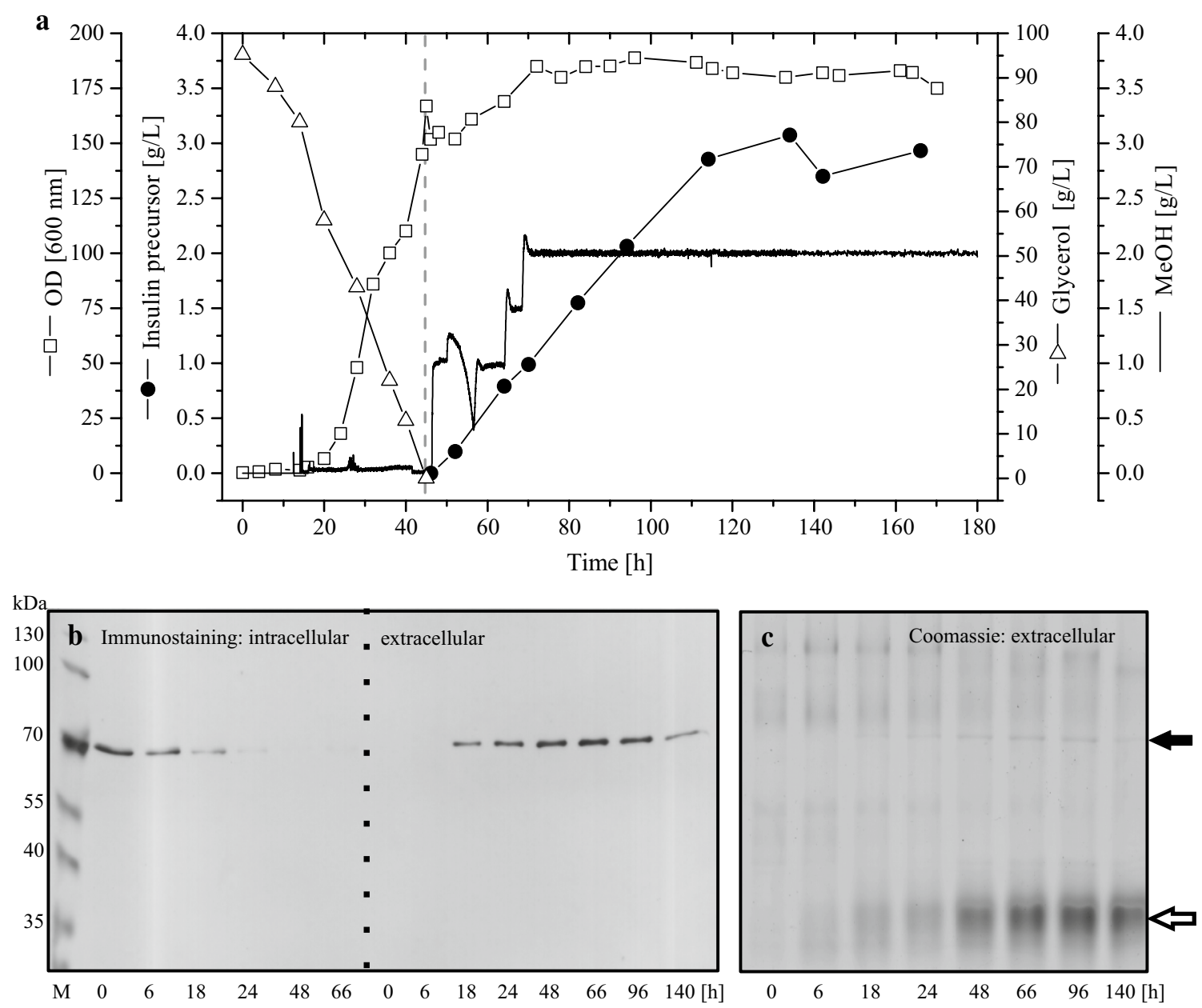

Fig. 4 Post-induction level of intra- and extracellular Kar2/Bip in controlled bioreactor fed-batch culture. Cell growth and IP production were carried out in controlled bioreactor fed-batch culture as described previously [19]. a Concentrations of glycerol (open triangles), biomass (optical density: open squares), IP (filled circles), and methanol (solid line) are given. The dashed vertical line indicates the end of the glycerol batch (pre-induction) and the start of the methanol feeding phase (post-induction). $\mathbf{b}$ Immunoblot probing for the time-dependent change of intra- and extracellular Kar2/Bip in post-induction samples. c Extracellular proteins detected by Coomassie blue staining of SDS-PAGE gel indicating proteins identified by mass spectrometry. The positions of full-length Kar2/Bip ( $74 \mathrm{kDa}$, filled arrow) and the truncated approximately centrally cleaved Kar2/Bip fragment ( $35 \mathrm{kDa}$, open arrow) are indicated. b, c M denotes the molecular weight marker and the numbers on the bottom of the lanes the post-induction sampling time points. Please note the IP (7 kDa) is not detectable on conventional SDS-PAGE gels (see also [19]). Please also note that immunoblot and SDS-PAGE gel are aligned for the same molecular weight scale

Bip is for the most part degraded by proteases. This is in agreement with the failure to detect Kar2/Bip by immunostaining in the extracellular protein fraction, since the antibody used detects the ER retention signal which is located at the carboxyterminus. In addition to peptides originating from Kar2/Bip, other peptides of (truncated) Pichia proteins were detected within the tryptic digest of this protein band including the ER-derived protein disulphide isomerase Pdi (58 $\mathrm{kDa}$ full size) and also the vacuolar proteinase B (YscB, $52 \mathrm{kDa}$ full size) (for a detailed list of all identified proteins see also Additional file 2.

\section{Discussion}

Only few studies address the impact of environmental conditions on the extent of basal, misfolded protein independent UPR in yeast. For Saccharomyces cerevisiae it has been shown that-apart from aberrant protein secretion-the extent of the UPR is also connected to the nutritional state of the cell [20-22]. For example, addition of ammonium to nitrogen-starved S. cerevisiae causes UPR activation [22]. Other environmental conditions such as medium osmolarity and temperature also affect UPR as has been shown for non-producing and 
heterologous protein secreting $P$. pastoris in chemostat cultures [23, 24].

Our findings show that rapid growth during the exponential phase in batch culture is connected to an activated or higher basal level of the UPR marker protein Kar2/Bip (Fig. 1). Entry into stationary phase is linked to growth rate decrease which appears to be responsible for UPR downregulation as indicated by a declining Kar2/Bip level. UPR activation during rapid growth is independent of recombinant protein production and presumably due to the enhanced ER-associated endogenous yeast protein synthesis as it has been observed in the absence of secretory recombinant protein production and with the host not even carrying a recombinant gene (Fig. 3). The strong decline of the UPR sensor protein Kar2/Bip during entry into stationary phase also suggests active degradation of Kar2/Bip most likely through autophagic processes which are involved in the recycling of damaged or redundant cellular components. Electron microscopy studies gave clear evidence for autophagy in $P$. pastoris at the end of the glycerol batch phase and also during the methanol-induced IP production phase (Fig. 2). The electron micrographs of cells from the end of the glycerol batch phase revealed a yeast population with a diverse morphology including cells without visible vacuoles (Fig. 2a), cells with vacuoles containing autophagic bodies (Fig. 2b) and also cells at the onset of ribo- and ER-phagy with vacuoles starting to upload still intact ribosomes and double membranous structures with the typical features of the delimiting ER membranes (Fig. 2c). Thus, evidence for the strong decline of the ER resident marker protein Kar2/Bip at the end of the glycerol batch phase and concurrent detection of ER-phagy strongly suggest that the decreasing level of Kar2/Bip can be attributed to nutritional downshift induced autophagy.

Interestingly, we did not observe a higher basal level of the UPR marker protein Kar2/Bip with a higher initial glycerol concentration during batch growth. Instead, the intracellular level of Kar2/Bip remained unaffected by the initial glycerol concentration (Table 1, Additional file 1). Higher glycerol concentrations cause an increase in the medium osmolarity (Table 1) and it was reported previously that an increase in the medium osmolarity through salt addition resulted in enhanced levels of the UPR proteins Kar2/Bip and Pdi in non-producing P. pastoris during carbon limited growth in continuous cultures [24]. The independence of the Kar2/Bip level on increasing initial glycerol concentrations in batch culture might be explainable through the concurrent decrease of the maximum growth rate (Table 1) counteracting UPR activation through elevated medium osmolarity. Down-regulation of UPR responsive genes at lower growth rate in glucoselimited chemostat cultures of $P$. pastoris producing a
GAP promoter controlled recombinant protein has been observed before [25]. Thus, slower growth at higher initial glycerol concentrations might reduce UPR activation through elevated medium osmolarity. Also, the basal recombinant protein production independent UPR - as judged by the intracellular level of Kar2/Bip-was higher during exponential growth on glycerol than during slow growth on methanol (see host strain X-33 in Fig. 3c) confirming that slower growth is connected to a lower basal level of the UPR marker protein Kar2/Bip.

On the other hand, methanol-induced secretory IP production counteracts the UPR down-regulation during slow growth on methanol and results in de novo Kar2/ Bip synthesis followed by an IP secretion dependent release of Kar2/Bip into the culture medium. Accumulation of full-length Kar2/Bip in the culture medium was detectable by Western blot analysis (Figs. 3 and 4) and even by conventional SDS-PAGE analysis and Coomassie blue staining (Fig. 4) suggesting a substantial amount of extracellular accumulation. Release of Kar2/Bip in cultures of $P$. pastoris has been detected before during the secretory production of two other recombinant proteins using Western blot analysis $[14,17]$. In these experiments it was also shown that traces of Kar2/Bip were found in the medium in the absence of secretory protein production when growth occurred in rich medium [14]. In addition, overexpression of spliced Hacl, the transcription factor controlling the expression of UPR genes, was also leading to extracellular accumulation of Kar2/Bip in P. pastoris [26]. It has been suggested for the yeast Saccharomyces cerevisiae, that, regardless of the initial cause, strong UPR activation appears to be the critical factor for extracellular release of Kar2/Bip [27]. In our experiments we did not detect Kar2/Bip in the medium in the absence of secretory IP production (Fig. 3, data not shown). However, during methanol-induced IP production the majority of Kar2/Bip was found in the medium (Figs. 3 and 4) suggesting a strong UPR-inducing impact of secretory IP production.

The detection of Kar2/Bip in the culture medium may indicate that Kar2/Bip does not only promote folding in the ER or transfer of aberrant proteins to the ERAD pathway but may also accompany some (aberrant) proteins on the entire passage through the secretory pathway to the cell exterior. Binding of Kar2/Bip to another recombinant protein has been verified by pull down assay [28], thus, a potential interaction of IP and Kar2/Bip might be responsible for the concurrent appearance of both proteins in the culture medium. On the other hand detection of large amounts of truncated versions of the ER-resident proteins Kar2/Bip and Pdi as well as the vacuolar protease $\mathrm{B}$ in the culture medium may also indicate that IP production mediated UPR stress enhances ER-specific 
autophagy possibly leading to the extracellular release of vacuolar content. Upregulation of genes involved in ER-phagy [7] and ER autophagosomes [29] have been detected under conditions of ER stress resulting from the secretory production of recombinant proteins. Also, electron micrographs of IP producing cells from the methanol fed-batch phase of controlled bioreactor cultures did not only reveal evidence for pexophagy but also indications for ER-phagy (Fig. 2d). Thus, accumulation of ER resident chaperones such as Kar2/Bip in the culture medium under conditions of ER-stress may not only result from (co)secretion but could also arise through the release of vacuolar content into the culture medium.

\section{Conclusions}

Rapid growth leads to a higher basal level of the UPR marker protein Kar2/Bip independent of recombinant protein production. Entry into stationary phase or slower growth on poorer substrate, e.g. methanol, leads to a lower level of Kar2/Bip. Methanol-induced secretory IP production elicits a strong UPR activation which counteracts the reduced UPR during slow growth on methanol. The major ER chaperone Kar2/Bip is found together with recombinant IP in the culture medium where full-length Kar2/Bip accumulates in addition to large amounts of truncated Kar2/Bip. Thus, for judging UPR activating properties of the produced protein it is important to additionally analyze the medium not only for intact Kar2/Bip but also for truncated versions of this UPR reporter protein.

\section{Methods}

\section{Strains and growth conditions}

\section{Strains}

The $P$. pastoris host strain $\mathrm{X}-33$ was from Invitrogen (Carlsbad, CA). Details of the construction of the recombinant $P$. pastoris strain $\mathrm{X}-33$ carrying a codon-optimized copy of a synthetic IP gene for secretory IP production under the control of the aox1 promoter $\left(\mathrm{Mut}^{+}\right)$and usage of the $\alpha$-factor secretory signal are given elsewhere [19].

\section{Precultures}

A starter culture was prepared in a $500 \mathrm{~mL}$ sterile baffled shake flask containing $100 \mathrm{~mL}$ of yeast nitrogen base with ammonium sulfate and without amino acids $(1.34 \mathrm{~g} / \mathrm{L})$, glycerol $(20 \mathrm{~g} / \mathrm{L})$ and biotin $(0.4 \mathrm{mg} / \mathrm{L})$ from glycerol stock cultures (initial $\mathrm{OD}_{600} 0.03,30{ }^{\circ} \mathrm{C}, 160 \mathrm{rpm}, 18 \mathrm{~h}$ to $\mathrm{OD}_{600} \sim 5$ ). The starter culture was used to inoculate $500 \mathrm{~mL}$ of defined medium in a $2 \mathrm{~L}$ baffled shake flask (starting $\mathrm{OD}_{600} 0.1,30{ }^{\circ} \mathrm{C}, 160 \mathrm{rpm}, 20 \mathrm{~h}$ to $\mathrm{OD}_{600} \sim 10$ ). The defined medium was identical to the medium employed for the glycerol batch phase in bioreactor cultures $[19,30]$ except that the glycerol concentration was $25 \mathrm{~g} / \mathrm{L}$.

\section{Bioreactor batch cultivations}

Bioreactor cultivations were started with an initial $\mathrm{OD}_{600}$ 0.5. Cells were grown either in a $2 \mathrm{~L}$ Biostat $\mathrm{B}$ plus or in a $10 \mathrm{~L}$ Biostat C (B. Braun Biotech International, Germany) using a defined medium as described previously [19] except that glycerol concentrations were varied between 30 and $125 \mathrm{~g} / \mathrm{L}$. Details are specified in the figure captions.

\section{Shake flask fed-batch cultivations}

After bioreactor batch growth in defined medium containing glycerol cells were pelleted by centrifugation (30 min, $4{ }^{\circ} \mathrm{C}, 3347 \times g$ ), washed with sterile phosphate buffered saline (PBS; $137 \mathrm{mmol} / \mathrm{L}$ sodium chloride, $2.7 \mathrm{mmol} / \mathrm{L}$ potassium chloride, $10 \mathrm{mmol} / \mathrm{L}$ disodium hydrogen phosphate and $1.8 \mathrm{mmol} / \mathrm{L}$ potassium phosphate), re-centrifuged and re-suspended in $150 \mathrm{~mL}$ baffled shake flasks containing $35 \mathrm{~mL}$ buffered methanol complex medium (BMMY) with $1 \%(\mathrm{w} / \mathrm{v})$ yeast extract, $2 \%(\mathrm{w} / \mathrm{v})$ peptone, $100 \mathrm{mmol} / \mathrm{L}$ potassium phosphate ( $\mathrm{pH}$ 6.0), $1.34 \mathrm{~g} / \mathrm{L}$ yeast nitrogen base with ammonium sulfate and without amino acids and $0.4 \mathrm{mg} / \mathrm{L}$ biotin to an OD600 100 $\left(30{ }^{\circ} \mathrm{C}, 160 \mathrm{rpm}\right.$, addition of $1 \%(\mathrm{v} / \mathrm{v})$ methanol twice a day at $12 \mathrm{~h}$ intervals for a total period of $96 \mathrm{~h})$. Details are specified in the figure captions.

\section{Bioreactor fed-batch cultivations}

Growth and IP production under industrially relevant conditions using a defined medium were carried out as described before $[19,30]$. Cells were grown in a $15 \mathrm{~L}$ Biostat C (B. Braun Biotech International, Germany) using glycerol as sole carbon source with an initial glycerol concentration of $95 \mathrm{~g} / \mathrm{L}$. After depletion of glycerol, IP production was induced by a pulsed methanol addition and subsequent methanol feeding to maintain the methanol concentration at $2 \mathrm{~g} / \mathrm{L}$.

\section{SDS-PAGE and immunodetection Sample preparation}

Cells were collected by centrifugation $(13,000 \mathrm{rpm}$ for $5 \mathrm{~min})$ and re-suspended in lysis buffer $(25 \mathrm{mmol} / \mathrm{L}$ potassium phosphate buffer $\mathrm{pH}$ 8.0, $5 \mathrm{mmol} / \mathrm{L}$ EDTA, $8 \%$ (w/v) glycerol, $500 \mathrm{mmol} / \mathrm{L}$ sodium chloride) to an $\mathrm{OD}_{600}$ 50. For cell disruption, aliquots of this suspension were diluted $1: 1$ with loading buffer $(20 \mathrm{mmol} / \mathrm{L}$ Tris- $-\mathrm{HCl} \mathrm{pH}$ 8.0, $2 \mathrm{mmol} / \mathrm{L}$ EDTA, 5\% (w/v) SDS, 0.02\% (w/v) bromophenol blue, 5.5\% (v/v) glycerol, 20\% (v/v) 2-mercaptoethanol) and boiled for $1 \mathrm{~h}$ at $96^{\circ} \mathrm{C}$. Medium samples were diluted 1:1 with modified loading buffer (as above but 
with $10 \%(\mathrm{v} / \mathrm{v}) 2$-mercaptoethanol) and boiled at $96{ }^{\circ} \mathrm{C}$ for $5 \mathrm{~min}$.

\section{SDS-PAGE, Western blotting and immunostaining}

Samples (loading volume $7 \mu \mathrm{L}$ ) were run on $12 \%$ SDSPAGE gels prior to Coomassie Brilliant Blue staining or electroblotting onto PVDF membranes (Bio-Rad, Hercules, USA) at $15 \mathrm{~V}$ for $45 \mathrm{~min}$. The membranes were blocked with 5\% (w/v) skimmed milk (Difco, France), $2 \%(\mathrm{w} / \mathrm{v})$ polyvinylpyrrolidone (Carl Roth, Germany) in PBS containing 1\% (v/v) Tween 20 (PBS-T) for $2 \mathrm{~h}$. After washing the membranes with PBS-T, the mouse antiHDEL antibody (2E7) (sc-53472; 1:1000 dilution, Santa Cruz Biotechnology, USA) was added and the membranes incubated for $1 \mathrm{~h}$ at room temperature. After washing with PBS-T, the secondary anti-mouse antibody (1:5000 dilution, Calbiochem, Germany) was added and incubation continued for $1 \mathrm{~h}$. Immunostaining was done using $3,3^{\prime}, 5,5^{\prime}$ tetramethylbenzidine (Sigma, Germany) as substrate. The mouse anti-HDEL antibody (2E7) is a commercial antibody raised against a synthetic HDEL peptide corresponding to the $\mathrm{C}$-terminus of yeast $\mathrm{BiP}$ (also designated GRP 78) which should bind only to the six $P$. pastoris proteins containing the C-terminal HDEL sequence, namely Kre5 (166.2 kDa), Sec12 (116.2 kDa), Lhs1 (99.5 kDa), Kar2/Bip (74.2 kDa), Pdi1 (57.8 kDa), and Mpd1 (33.5 kDa) [28].

For relative quantification, the intracellular Kar2/Bip abundance was normalized by densitometry analysis of immunostained membranes and SDS-PAGE gel images using ImageJ (National Institutes of Health, USA). For comparison, all samples were run on duplicate $12 \%$ SDSPAGE gels. One gel was stained with Coomassie Brilliant Blue and the second gel used for Western blotting and immunostaining. The Kar2/Bip Western blot relative abundance was determined as the quotient of the Kar2/ Bip band area on the immunostained membrane and the total protein content in the corresponding sample of the Coomassie Brilliant Blue stained SDS-PAGE gel. The intracellular mid-exponential sample of the $95 \mathrm{~g} / \mathrm{L}$ glycerol batch was used as internal standard on each gel and set to the relative Kar2/Bip abundance 100.

\section{Mass spectrometry for protein identification (LC-MS/MS)}

The peptides extracted after tryptic in-gel digestion of the relevant band from Coomassie stained gels were analyzed on an UltiMate 3000 RSLC nano LC system connected to an Orbitrap Fusion mass spectrometer (Thermo Scientific). MS survey scans were alternated with MS/MS scans of daughter ion spectra obtained from peptide components by higher collision energy induced dissociation (HCD). All spectra were recorded using the orbitrap detector with a resolution of $120 \mathrm{k}$ for survey scans and $15 \mathrm{k}$ for daughter ion spectra. The experimental setup was as follows: the peptide mixture was loaded onto a $75 \mu \mathrm{m} \times 2 \mathrm{~cm}$ precolumn (Acclaim PepMap 100, C18, $3 \mu \mathrm{m}$, Thermo Scientific) and eluted over 60 min using a $75 \mu \mathrm{m} \times 50 \mathrm{~cm}$ analytical column (Acclaim PepMap RSLC, C18, $2 \mu \mathrm{m}$, Thermo Scientific) with a gradient buffer $0-95 \%$ acetonitrile in $0.1 \%$ formic acid. The data were acquired using the Xcalibur 2.3 software (Thermo Scientific) and processed with the Peaks 6 software (Bioinformatics Solution). MS/ MS data were searched versus the Pichia (syn. Komagataella) pastoris database extracted from the NCBI non redundant database.

\section{Transmission electron microscopy}

Culture samples were immediately fixed at ambient temperature in $2.5 \%(\mathrm{v} / \mathrm{v})$ glutardialdehyde in $20 \mathrm{mmol} / \mathrm{L}$ HEPES buffer ( $\mathrm{pH}$ 7.1) for $30 \mathrm{~min}$. Further processing and image analysis was carried out as described previously $[13,31]$.

\section{Other analytical procedures}

Cell growth was followed by measurement of the optical density at $600 \mathrm{~nm}\left(\mathrm{OD}_{600}\right)$ using a Multiskan GO UVVis spectrophotometer (Thermo Fisher Scientific, Germany). The glycerol concentration was analyzed by high performance liquid chromatography (Chromaster system, Hitachi, USA) with an Aminex HPX-87H column (Bio-Rad Laboratories, USA) at $60{ }^{\circ} \mathrm{C}$ using $5 \mathrm{mmol} / \mathrm{L}$ $\mathrm{H}_{2} \mathrm{SO}_{4}$ as the mobile phase at a flow rate of $0.6 \mathrm{~mL} / \mathrm{min}$. The osmolarity of the medium was determined using an Osmomat 3000 (Gonotec, Germany) freezing-point osmometer. Quantification of IP was carried out essentially as described previously [19] with minor modifications. Filtered aliquots of cell-free supernatants were mixed $1: 1$ with solution A $(0.15 \%(\mathrm{v} / \mathrm{v})$ trifluoroacetic acid in ultrapure water) and analyzed by reversed-phase high performance liquid chromatography (RP-HPLC) using a $3 \mu \mathrm{m}$ SUPELCOSIL $^{\mathrm{TM}}$ LC-304 (Sigma-Aldrich, USA) column $(3.3 \mathrm{~cm} \times 4.6 \mathrm{~mm})$ at $24{ }^{\circ} \mathrm{C}$ with a Chromaster liquid chromatography system (Hitachi, USA). Elution was performed with a gradient formed by mixing solutions A and B $(0.15 \%(\mathrm{v} / \mathrm{v})$ trifluoroacetic acid in acetonitrile) as follows: $10 \% \mathrm{~B}(0-6 \mathrm{~min}), 10-43 \%$ B (6-41 min), $43-100 \%$ B (41-43 min), $100-10 \%$ B (43-53 $\mathrm{min}), 10 \% \mathrm{~B}(53-60 \mathrm{~min})$. The flow rate was maintained at $1 \mathrm{~mL} / \mathrm{min}$ and the column effluent was monitored at 214 and $280 \mathrm{~nm}$. Freeze-dried purified IP was used as standard (concentration determined by weight and by Pierce bicinchoninic acid kit, Thermo Fisher Scientific, Germany). 


\section{Additional files}

Additional file 1. Growth performance and intracellular Kar2/Bip level of $P$. pastoris $X$ - 33 carrying the aox 1 promoter-controlled IP gene during batch growth in a $2 \mathrm{~L}$ bioreactor with different initial glycerol concentrations (30 to $125 \mathrm{~g} / \mathrm{L}$ ). (A) The time-dependent changes in the biomass (top), glycerol concentration (middle), and osmolarity of the culture broth (bottom) are given (initial glycerol concentration $30 \mathrm{~g} / \mathrm{L}$, open squares; $60 \mathrm{~g} / \mathrm{L}$, full squares; $95 \mathrm{~g} / \mathrm{L}$, open circles; and $125 \mathrm{~g} / \mathrm{L}$ full circles). B) SDSPAGE gels and (C) corresponding immunoblots probing for Kar2/Bip in total cell lysates (all samples from the mid-exponential growth phase). The numbers on top of the lanes denote the initial glycerol concentration and " $r$ " the repetition batch experiment. M denotes the molecular weight marker and the other numbers on the bottom of the lanes the batch culture post-inoculation sampling time points.

Additional file 2. HPLC-MS/MS analysis of protein band at approx. $35 \mathrm{kDa}$.

\section{Abbreviations}

ER: endoplasmic reticulum; ERAD: endoplasmic reticulum associated degradation; HBsAg: hepatitis B surface antigen; IP: insulin precursor; iTRAQ LC-MS/ MS: isobaric tags for relative and absolute quantitation liquid chromatography-tandem mass spectrometry; Maldi-ToF: matrix-assisted laser desorption/ ionization-time-of-flight; NCBI: National Center for Biotechnology Information; PBS: phosphate buffered saline; SDS-PAGE: sodium dodecyl sulfate polyacrylamide gel electrophoresis; UPR: unfolded protein response.

\section{Authors' contributions}

GR performed most experiments and prepared an initial draft manuscript. AV performed the initial experiments on UPR induction and autophagy analysis with the IP producing Pichia strain. HL carried out the electron microscopy studies. MN contributed to protein identification by LC-MS/MS. UR conceived and directed the study and prepared the final manuscript. All authors read and approved the final manuscript.

\section{Author details}

${ }^{1}$ Technical Chemistry-Life Science, Leibniz University of Hannover, Hannover, Germany. ${ }^{2}$ Helmholtz Centre for Infection Research, Inhoffenstrasse 7, 38124 Brunswick, Germany.

\section{Acknowledgements}

Not applicable.

\section{Competing interests}

The authors declare they have no competing interests.

\section{Availability of data and materials}

All data generated or analyzed during this study are included in the published article or available upon request.

\section{Consent for publication}

Not applicable.

\section{Ethics approval and consent to participate} Not applicable.

\section{Funding}

Gustavo Roth would like to acknowledge the National Council for Scientific and Technological Development, Brazil (CNPq) and Ana Letícia Vanz the Federal Agency for the Improvement of Higher Education, Brazil (CAPES) for providing Ph.D. fellowships.

\section{Publisher's Note}

Springer Nature remains neutral with regard to jurisdictional claims in published maps and institutional affiliations.
Received: 15 May 2018 Accepted: 31 July 2018

Published online: 09 August 2018

\section{References}

1. Cereghino GP, Cereghino JL, Ilgen C, Cregg JM. Production of recombinant proteins in fermenter cultures of the yeast Pichia pastoris. Curr Opin Biotechnol. 2002;13:329-32.

2. Cereghino JL, Cregg JM. Heterologous protein expression in the methylotrophic yeast Pichia pastoris. FEMS Microbiol Rev. 2000;24:45-66.

3. Puxbaum V, Mattanovich D, Gasser B. Quo vadis? The challenges of recombinant protein folding and secretion in Pichia pastoris. Appl Microbiol Biotechnol. 2015;99:2925-38.

4. Resina D, Bollok M, Khatri NK, Valero F, Neubauer P, Ferrer P. Transcriptional response of $P$. pastoris in fed-batch cultivations to Rhizopus oryzae lipase production reveals UPR induction. Microb Cell Fact. 2007;6:21.

5. Gasser B, Maurer M, Rautio J, Sauer M, Bhattacharyya A, Saloheimo M, Penttila M, Mattanovich D. Monitoring of transcriptional regulation in Pichia pastoris under protein production conditions. BMC Genomics. 2007;8:179.

6. Zhu T, Guo M, Zhuang Y, Chu J, Zhang S. Understanding the effect of foreign gene dosage on the physiology of Pichia pastoris by transcriptional analysis of key genes. Appl Microbiol Biotechnol. 2011;89:1127-35.

7. Whyteside G, Alcocer MJC, Kumita JR, Dobson CM, Lazarou M, Pleass RJ, Archer DB. Native-state stability determines the extent of degradation relative to secretion of protein variants from Pichia pastoris. PLoS ONE. 2011;6:e22692.

8. Hesketh AR, Castrillo JI, Sawyer T, Archer DB, Oliver SG. Investigating the physiological response of Pichia (Komagataella) pastoris GS115 to the heterologous expression of misfolded proteins using chemostat cultures. Appl Microbiol Biotechnol. 2013;97:9747-62.

9. Lin XQ, Liang SL, Han SY, Zheng SP, Ye YR, Lin Y. Quantitative iTRAQ LCMS/MS proteomics reveals the cellular response to heterologous protein overexpression and the regulation of HAC1 in Pichia pastoris. J Proteomics. 2013;91C:58-72

10. VogIT, Thallinger GG, Zellnig G, Drew D, Cregg JM, Glieder A, Freigassner M. Towards improved membrane protein production in Pichia pastoris: general and specific transcriptional response to membrane protein overexpression. N Biotechnol. 2014;31:538-52.

11. Yang J, Lu Z, Chen J, Chu P, Cheng Q, Liu J, Ming F, Huang C, Xiao A, Cai H, Zhang L. Effect of cooperation of chaperones and gene dosage on the expression of porcine PGLYRP-1 in Pichia pastoris. Appl Microbiol Biotechnol. 2016;100:5453-65.

12. Hohenblum H, Gasser B, Maurer M, Borth N, Mattanovich D. Effects of gene dosage, promoters, and substrates on unfolded protein stress of recombinant Pichia pastoris. Biotechnol Bioeng. 2004;85:367-75.

13. Vanz AL, Lünsdorf H, Ahmad A, Nimtz M, Gurramkonda C, Khanna N, Rinas U. Physiological response of Pichia pastoris GS115 to methanolinduced high level production of the Hepatitis B surface antigen: catabolic adaptation, stress responses, and autophagic processes. Microb Cell Fact. 2012;11:103.

14. Liu YY, Woo JH, Neville DM Jr. Overexpression of an anti-CD3 immunotoxin increases expression and secretion of molecular chaperone BiP/ Kar2p by Pichia pastoris. Appl Environ Microbiol. 2005;71:5332-40.

15. Dudek J, Benedix J, Cappel S, Greiner M, Jalal C, Muller L, Zimmermann R. Functions and pathologies of BiP and its interaction partners. Cell Mol Life Sci. 2009;66:1556-69.

16. Damasceno LM, Anderson KA, Ritter G, Cregg JM, Old L, Batt CA. Cooverexpression of chaperones for enhanced secretion of a singlechain antibody fragment in Pichia pastoris. Appl Microbiol Biotechnol. 2007;74:381-9.

17. Samuel P, Prasanna Vadhana AK, Kamatchi R, Antony A, Meenakshisundaram S. Effect of molecular chaperones on the expression of Candida antarctica lipase B in Pichia pastoris. Microbiol Res. 2013;168:615-20.

18. Vanz AL, Nimtz M, Rinas U. Decrease of UPR- and ERAD-related proteins in Pichia pastoris during methanol-induced secretory insulin precursor production in controlled fed-batch cultures. Microb Cell Fact. 2014;13:23. 
19. Gurramkonda C, Polez S, Skoko N, Adnan A, Gäbel T, Chugh D, Swaminathan S, Khanna N, Tisminetzky S, Rinas U. Application of simple fed-batch technique to high-level secretory production of insulin precursor using Pichia pastoris with subsequent purification and conversion to human insulin. Microb Cell Fact. 2010;9:31.

20. Schröder M, Kaufman RJ. ER stress and the unfolded protein response. Mutat Res. 2005:569:29-63.

21. Schröder M, Chang JS, Kaufman RJ. The unfolded protein response represses nitrogen-starvation induced developmental differentiation in yeast. Genes Dev. 2000;14:2962-75.

22. Kaufman RJ, Scheuner D, Schröder M, Shen X, Lee K, Liu CY, Arnold SM. The unfolded protein response in nutrient sensing and differentiation. Nat Rev Mol Cell Biol. 2002;3:411-21.

23. Dragosits M, Stadlmann J, Albiol J, Baumann K, Maurer M, Gasser B, Sauer M, Altmann F, Ferrer P, Mattanovich D. The effect of temperature on the proteome of recombinant Pichia pastoris. J Proteome Res. 2009;8:1380-93

24. Dragosits M, Stadlmann J, Graf A, Gasser B, Maurer M, Sauer M, Kreil DP, Altmann F, Mattanovich D. The response to unfolded protein is involved in osmotolerance of Pichia pastoris. BMC Genomics. 2010;11:207.

25. Rebnegger C, Graf AB, Valli M, Steiger MG, Gasser B, Maurer M, Mattanovich D. In Pichia pastoris, growth rate regulates protein synthesis and secretion, mating and stress response. Biotechnol J. 2014;9:511-25.

26. Guerfal M, Ryckaert S, Jacobs PP, Ameloot P, Van Craenenbroeck K, Derycke R, Callewaert N. The HAC1 gene from Pichia pastoris: characterization and effect of its overexpression on the production of secreted, surface displayed and membrane proteins. Microb Cell Fact. 2010;9:49.
27. Belden WJ, Barlowe C. Deletion of yeast p24 genes activates the unfolded protein response. Mol Biol Cell. 2001;12:957-69.

28. Pfeffer M, Maurer M, Stadlmann J, Grass J, Delic M, Altmann F, Mattanovich D. Intracellular interactome of secreted antibody Fab fragment in Pichia pastoris reveals its routes of secretion and degradation. Appl Microbiol Biotechnol. 2012;93:2503-12.

29. Zhong Y, Yang L, Guo Y, Fang F, Wang D, Li R, Jiang M, Kang W, Ma J, Sun J, Xiao W. High-temperature cultivation of recombinant Pichia pastoris increases endoplasmic reticulum stress and decreases production of human interleukin-10. Microb Cell Fact. 2014;13:163.

30. Gurramkonda C, Adnan A, Gäbel T, Lünsdorf H, Ross A, Nemani SK, Swaminathan S, Khanna N, Rinas U. Simple high-cell density fed-batch technique for high-level recombinant protein production with Pichia pastoris: application to intracellular production of Hepatitis B surface antigen. Microb Cell Fact. 2009;8:13.

31. Lünsdorf H, Gurramkonda C, Adnan A, Khanna N, Rinas U. Virus-like particle production with yeast: ultrastructural and immunocytochemical insights into Pichia pastoris producing high levels of the Hepatitis B surface antigen. Microb Cell Fact. 2011;10:48.

32. Bernales S, McDonald KL, Walter P. Autophagy counterbalances endoplasmic reticulum expansion during the unfolded protein response. PLoS Biol. 2006;4:e423.

33. Bernales S, Schuck S, Walter P. ER-phagy: selective autophagy of the endoplasmic reticulum. Autophagy. 2007;3:285-7.

34. Schuck S, Gallagher CM, Walter P. ER-phagy mediates selective degradation of endoplasmic reticulum independently of the core autophagy machinery. J Cell Sci. 2014;127:4078-88.
Ready to submit your research? Choose BMC and benefit from:

- fast, convenient online submission

- thorough peer review by experienced researchers in your field

- rapid publication on acceptance

- support for research data, including large and complex data types

- gold Open Access which fosters wider collaboration and increased citations

- maximum visibility for your research: over $100 \mathrm{M}$ website views per year

At BMC, research is always in progress.

Learn more biomedcentral.com/submissions 